\title{
RECURRENT POST-TRAUMATIC NON-EOSINOPHILIC PLEURAL EFFUSION: REPORT OF THREE CASES
}

\author{
doi: $10.1590 / \mathbf{S 1 8 0 7 - 5 9 3 2 2 0 0 8 0 0 0 3 0 0 0 2 3}$
}

Artur Eugênio de Azevedo Pereira, ${ }^{\mathrm{I}}$ Ricardo Mingarini Terra, ${ }^{\mathrm{I}}$ Lisete Ribeiro Teixeira, ${ }^{\mathrm{II}}$ Paulo Manuel Pêgo-Fernandes, Fábio Biscegli Jatene ${ }^{\mathrm{I}}$

\section{INTRODUCTION}

Post-traumatic pleural effusion is an uncommon clinical entity, though it may occur after chest wall trauma, thoracentesis, or thoracotomy. Its most prominent feature is a high eosinophil count at pleural fluid cytology. ${ }^{1}$ There are no previous reports of non-eosinophilic post-traumatic pleural effusion.

\section{CASE DESCRIPTION}

\section{Case 1}

A 25-year-old woman had a car accident with chest wall trauma and was evaluated elsewhere. Chest $\mathrm{x}$-ray showed rib fractures, but no pleural effusion, and the woman was subsequently discharged. After one month, she complained of dyspnea and chest pain and underwent thoracentesis elsewhere. Fifteen days later, she was admitted to our hospital on account of symptom recurrence. As a result of another thoracentesis, $1,800 \mathrm{ml}$ of fluid were drained (Table-1). As the patient reported no further complaints, she did not undergo pleural biopsy.

\section{Case 2}

A 60-year-old man had a car accident and experienced chest wall trauma. He was evaluated elsewhere, and chest $\mathrm{x}$-ray showed sternal and bilateral rib fractures without pleural effusion. The man was then discharged. After one

${ }^{\text {I }}$ Department of General Thoracic Surgery, Faculdade de Medicina da Universidade de São Paulo - São Paulo/SP, Brazil.

II Pulmonary Division, Faculdade de Medicina da Universidade de São Paulo - São Paulo/SP, Brazil.

artur.de.azevedo@hotmail.com month, he complained of worsening left chest pain, and a chest X-ray demonstrated left pleural effusion. As a result of thoracentesis, $1,000 \mathrm{ml}$ of fluid were drained (Table-1). Pleural effusion recurred and he underwent a diagnostic videothoracoscopy with pleural biopsy that demonstrated reactive pleuritis with negative cultures. There were no recurrences.

\section{Case 3}

A 36-year-old woman underwent a surgical procedure for thoracic scoliosis correction with partial costectomy of five ribs. After a five-week uneventful post-operative period, she had pleuritic chest pain. A chest X-ray showed pleural effusion, and thoracentesis revealed a lymphocytic exudate (Table-1). Pleural effusion recurred, and she underwent a diagnostic videothoracoscopy with pleural biopsy that demonstrated chronic pleuritis. There was no recurrence.

\section{DISCUSSION}

The etiology of post-traumatic eosinophilic pleural effusion is attributed to immune complex reaction, probably related to the presence of air or blood in the pleural space. ${ }^{2-6}$ To the authors' knowledge, there are no reports of lymphocytic pleural effusion associated with post-traumatic conditions.

The patients had extensive chest wall trauma and rib fractures. However, no sign of pleural space violation was detected during the early post-trauma period, which could explain the absence of eosinophils upon post-traumatic pleural effusion analysis. ${ }^{2}$ The patients developed symptoms one month after the trauma and had a recurrent lymphocitic exudative pleural effusion.

Although there is a high incidence of small pleural 
Table 1 - Clinical data and pleural fluid analysis

\begin{tabular}{llll}
\hline & Case-1 & Case-2 & Case-3 \\
\hline Gender & Female & Male & Female \\
Age (years) & 25 & 60 & 36 \\
Trauma & Car accident & Car accident & Costectomy \\
Fractures & Ribs & Sternum and Ribs & Ribs \\
LDH(mg/dl) & 257 & 341 & 315 \\
Protein(g/dl) & 4,9 & 5,5 & 5,1 \\
ADA(U/l) & 8,8 & 13 & 28,1 \\
Cytology & N29\% L68\% E01\% & N03\% L88\% E03\% & N16\% L75\% E02\% \\
Procedure & Thoracentesis & Videothoracoscopy & Videothoracoscopy \\
\hline
\end{tabular}

LDH:lactic dehydrogenase; ADA:adenosine deaminase; N:Neutrophils; L:Lymphocytes; E:Eosinophils.

effusion immediately after cardiac surgery, ${ }^{7}$ a series of lymphocitic pleural effusions with low LDH occurring more than 1 month after coronary artery bypass grafting (CABG) has been described. ${ }^{8}$ This type of pleural effusion could be related to the local trauma involved with $\mathrm{CABG}$, which could lead to a local immunological reaction, interruption of pleural lymphatics, or leakage of fluid from the mediastinum. Our patients had extensive subpleural trauma and hematoma due to rib fractures, and possibly a mediastinal hematoma in case 2, similar to that observed in CABG. Indeed, pleural fluid analysis demonstrated similar LDH and cell count results. Consequently, we believe the mechanism might be the same.

Post-traumatic lymphocitic pleural effusion is a rare clinical entity that is probably related to subpleural trauma or dissection, and may recur and be treated with pleural drainage.

\section{REFERENCES}

1. Falcón Panella I, Force Sanmartín L, Hernandéz JA. Derrame pleural eosinófilo post-traumático. An Med Interna (Madrid). 2004;21:61-2.

2. Heidecker J, Kaplan A, Sahn SA. Pleural fluid and peripheral eosinophilia from hemothorax: Hypothesis of the pathogenesis of EPE in hemothorax and pneumothorax. Am J Med Sci. 2006;332:148-52.

3. de Blay F, Aykut-Baturalp A, Goetz J, Purohit A, Perez-Infante A, Hauptmann G, et al. Post-traumatic pleural effusion: demonstration of local complement consumption. Respir Med. 1997;91:373-5.

4. Kalomenidis I, Guo Y, Peebles S, Lane KB, Papiris S, Elias J, et al. Pneumothorax-associated pleural eosinophilia in mice is interleukin-5 but not interleukin-13 dependent. Chest. 2005;128:2978-83.
5. Ishiura Y, Fujimura M, Nakamura N, Jokaji H, Minami S, Matsuda T. Intrapleural corticosteroid injection therapy for post-traumatic eosinophilic pleural effusion. Respir Med. 1996;90:501-3.

6. Rubins JB, Rubins HB. Etiology and prognostic significance of eosinophilic pleural effusions. Chest. 1996;110:1271-4.

7. Vargas FS, Cukier A, Hueb W, Teixeira LR, Light RW. Relationship between pleural effusion and pericardial involvement after myocardial revascularization. Chest. 1994;105:1748-52.

8. Light RW, Rogers JT, Cheng D, Rodriguez M. Large pleural effusions occurring after coronary artery bypass grafting. Ann Intern Med. 1999;130:891-6. 